\title{
O cartão-postal no Brasil do início do século XX: suporte para o encontro entre imagem e ação
}

\author{
The postcard in Brazil in the early twentieth century: \\ a medium on which image and action combine
}

\author{
Antonio Luigi Negro ${ }^{i}$ \\ ' Pesquisador, Departamento de \\ História/Universidade Federal da \\ Bahia. \\ Salvador - BA - Brasil \\ orcid.org/0000-0001-7253-355X \\ negro@ufba.br
}

Recebido em 30 maio 2019.

Aprovado em 19 jun. 2019.
NEGRO, Antonio Luigi. O cartão-postal no Brasil do início do século XX: suporte para o encontro entre imagem e ação. História, Ciências, Saúde Manguinhos, Rio de Janeiro, v.27, n.3, jul.-set. 2020, p.967-982.

Resumo

$\mathrm{O}$ artigo coloca o cartão-postal em evidência como suporte de encontro entre o retrato e a ação de quem se pronuncia sobre ele com uma mensagem. São abordados quatro cartões que foram, ao longo do tempo, usados como fonte pelos estudos históricos. Absorvida pela prática da fotografia, a pesquisa colocou primeiro em evidência o retratista. Em seguida, mirou a atuação do modelo. A proposta agora é incorporar aos estudos históricos o remetente e sua comunicação. Ao fazê-lo, reconhecese na superfície dessa mídia um espaço para a transparência de relações sociais vigentes no Brasil do início do século XX. O texto também sugere que Manuel Querino foi o primeiro intelectual a se valer de um cartão como fonte.

Palavras-chave: cartão-postal; Bahia; trabalho; história social.

\begin{abstract}
This article seeks to highlight the postcard as a medium on which an image and the action of someone commenting on the image come together. Four postcards that have been used as sources in historical research are discussed. Absorbed by the practice of photography, the study first focuses on the artist. Then it focus on the role of the model. Finally, it presents the incorporation of the sender and his message. When doing so, it recognizes the surface of this medium as a space for transparency in terms of the social relationships prevailing in Brazil in the early twentieth century. The article also suggests that Manuel Querino was the first intellectual to use a postcard as a bibliographic source.
\end{abstract}

Keywords: postcard; Bahia; work; social history. 
$\mathrm{U}$ m pequeno número de quatro cartões-postais é familiar à pesquisa histórica no Brasil. Foram abordados entre 1979 e 2014 por especialistas experientes e duas mestres em história (pelo menos). Três são postais de baianas, designadas "crioulas", sendo dois remetidos no mesmo ano de 1909 e o terceiro em 1913. Também em 1909 foi despachado o "ganhador africano", que - menos examinado - é o quarto e último elemento deste reduzido conjunto. Os três enviados em 1909 obedecem a uma série produzida e vendida pelo retratista e editor Lindemann, com as letras D. e K. correspondendo a mulheres e F. a um homem. Mandado imprimir por J. Mello, o exemplar de 1913 é um avulso, ou seja, não pertence a uma série. Os editores Lindemann e Mello atuaram em Salvador entre o fim do século XIX e o início do XX, mas isso não impediu as correspondências de circularem, em 1909, entre Campinas e Curitiba. Com lugar de origem ininteligível, o de 1913 foi entregue no Rio de Janeiro.

Neste artigo, minha intenção não é investigar os retratistas, suas técnicas fotográficas, sua prática nos estúdios (ou a céu aberto). Também não tenciono examinar os editores, a impressão gráfica, as séries de postais ou suas tiragens. Desejo analisar o postal como superfície de encontro entre (a) imagens de mulheres e homens da classe trabalhadora, (b) correspondência entre remetentes e destinatários e (c) marcações no suporte do cartão, manuscritas ou por intervenções não textuais, ambas referidas às imagens. Para tal, detenho-me, insisto, não na arte fotográfica nem na reprografia, tampouco na digitalização. Examino o modo como inscrições gravadas em acréscimo à imagem dão nitidez às relações sociais vigentes (não só entre os correspondentes). Abordando as pesquisas que se debruçaram sobre os quatro cartões mencionados, evidencio como foram historicamente tratados pela pesquisa científica. Desde o início, há em comum serem apontados como ponto de encontro entre imagem e ação, entre representação e o sujeito que concorre para a materialidade da representação. Inicialmente, o sujeito percebido foi o fotógrafo, mas outras autorias sobressaíram depois. Apesar disso, restam ainda a descoberto as intervenções dos remetentes, que são igualmente autorais. O encontro entre imagem e inscrições remete não apenas à correspondência entre lugares de origem e destino, mas à perspectiva dos correspondentes sobre as imagens ou as relações sociais. Invenção que marcou época, os bilhetes (ou cartões) postais são superfície com subsequentes marcas autorais, servindo de suporte a gravações que apontam indícios das relações sociais em vigor no Brasil do início do século XX.

De forma pioneira, apenas "D. crioula" e "F. carregador africano" foram trazidos à tona por Boris Kossoy (1980). São uma minúscula parte de ampla pesquisa resultante em tese de doutorado, defendida em 1979, logo publicada em livro. Com a baiana D., o fotógrafo Lindemann, já aqui mencionado também como editor de bilhetes-postais, prosseguiu "no seu programa de 'divulgar' em massa" certas “'curiosidades turísticas' do Brasil". Sem dirigir atenção ao texto do remetente, referindo-se ao carregador africano F., Kossoy (1980, p.98) argumenta que "pela fotografia nota-se como a imagem de um exescravo pode ser 'utilizada' a fim de 'promover' as características 'exóticas' de um país" (destaques no original). 

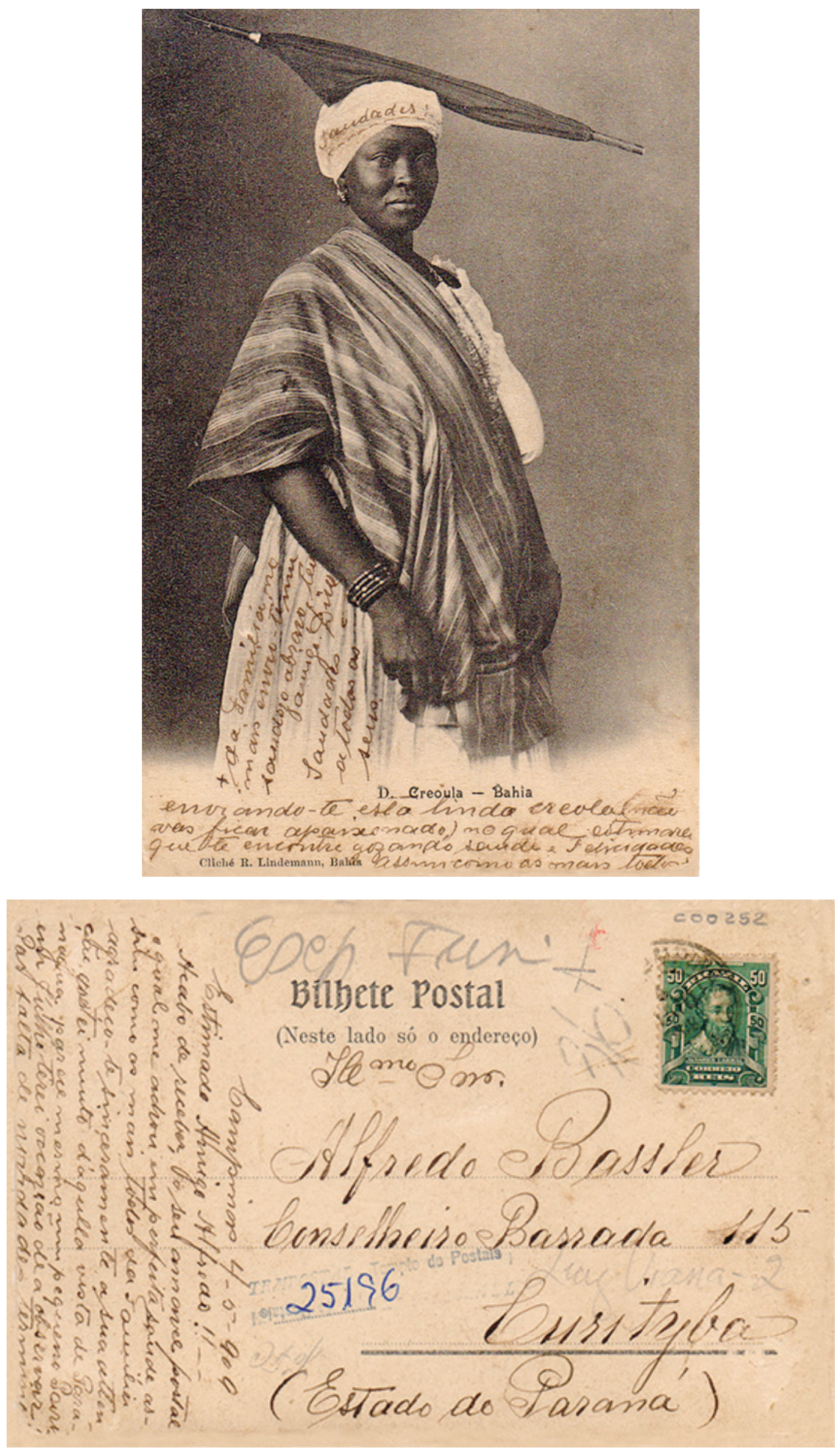

Figura 1: Frente e verso do cartão “D. crioula”, clichê R. Lindemann, 4 maio 1909 (Museu Tempostal, coleção Antônio Marcelino) 

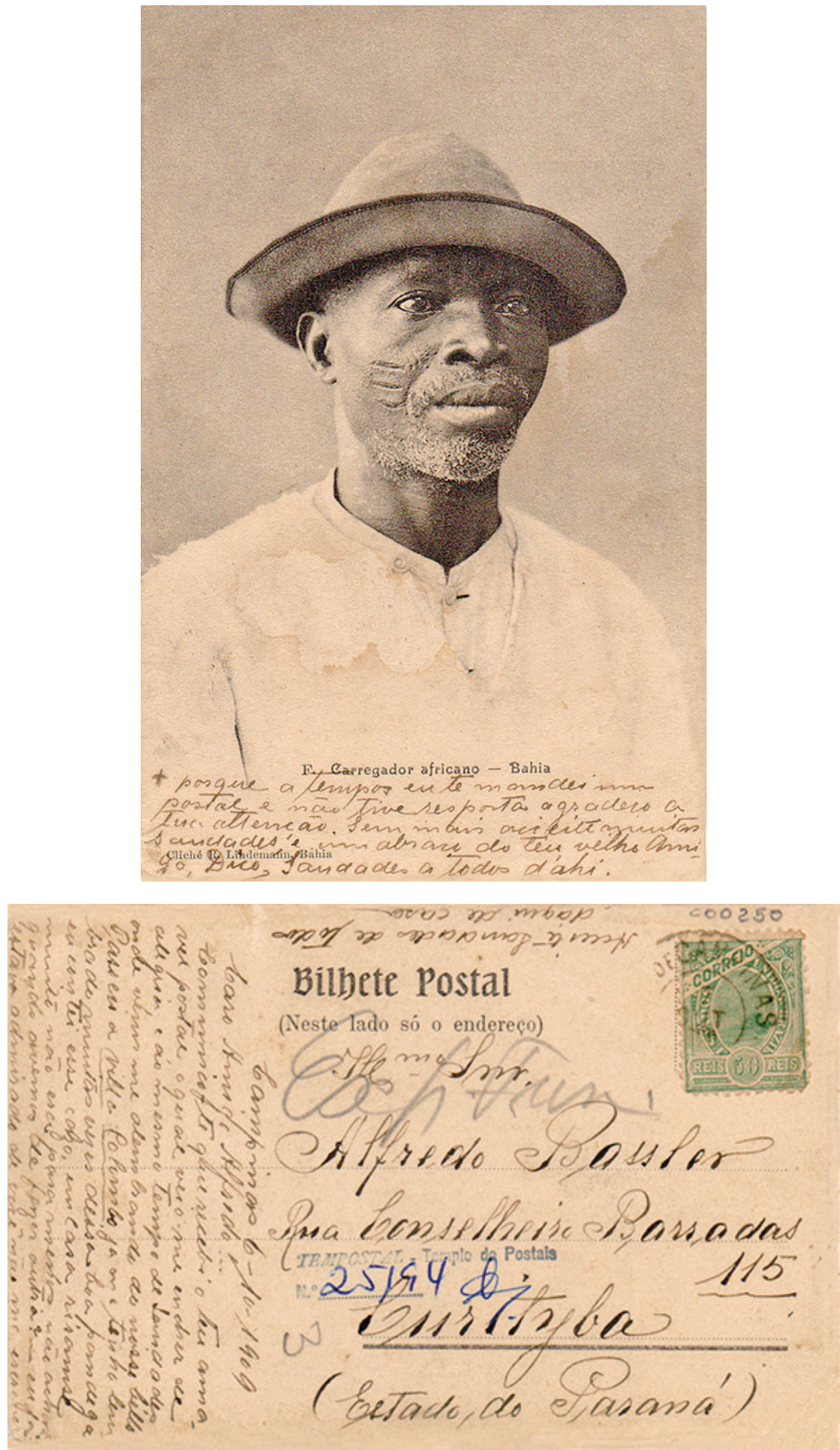

Figura 2: Frente e verso do cartão “F. carregador africano”, clichê R. Lindemann, 6 out. 1909 (Museu Tempostal, coleção Antônio Marcelino) 
As mesmas reproduções de D. e F. reapareceram em Kossoy e Carneiro (1994). Adicionalmente, é reproduzida "K. crioula". Informa-se que sua seleção quis demonstrar como os fotógrafos manipulavam a imagem do negro, "explorando-a comercialmente, 'coisificando-os' como ... 'modelos-objeto'" (Kossoy, Carneiro, 1994, p.193; destaque no original). Também aparecem a "négresse de Bahia" e a "indienne Botocudo". Tanto a negra como a indígena figuram lado a lado em uma mesma prancha de um álbum fotográfico de Ferrez (são, porém, de datas diferentes: 1885 e 1875, respectivamente). Também podem ser encontradas reproduzidas em três diferentes mídias: (1) a mais antiga, o carte-de-visite, (2) a mais rara e desconhecida, o estereoscópico, e (3) a mais recente, o cartão-postal. Na passagem do século XIX ao XX, estavam à venda em livrarias das cidades ou em lojas de estúdios fotográficos, bem como em exposições ou navios. Eram objetos sofisticados, bons como passatempo e para guardar ou presentear, atendendo "ao espírito do colecionismo de imagens" (Kossoy, Carneiro, 1994, p.194). Ramificavam no grande público as coleções de tipos humanos formadas em gabinetes científicos.

Kossoy e Carneiro (1994, p.194-195) comentam como, em meados de 1860, o retratista Christiano Jr. fazia autopromoção no verso de suas mercadorias por meio dos anúncios de "tipos de negros e índios", ladeados de "homens célebres, monarcas, guerreiros, literatos". Por ser barato e bem mais fácil de carregar e manusear do que as geringonças estereoscópicas, além de poder ser um presente, remetido pelos correios ou adicionado a coleções, o bilhetepostal virou modismo planetário a partir da década de 1890; e, com ele, o "olhar europeu não se desviou da figura do negro". Tal gosto não passou despercebido a Lindemann, daí ter apresentado uma série com abecedário de tipos humanos em que se encontram D., F. e K. A "imagem da técnica", arrematam Kossoy e Carneiro (1994, p.211), reforçava uma outra, preexistente e "cristalizada": a "mental". Quer dizer, colecionar tipos humanos em cartões dava continuidade à coisificação a que a imagem do negro, do índio ou do selvagem já era submetida, quer por viajantes, quer por cientistas.

Tal qual D. e F., o bilhete postal de K. porta texto expressivo deixado pelo remetente. Por ser possível lê-las, as atraentes mensagens aguçam a curiosidade, no entanto, não foram examinadas como fonte da pesquisa científica. De qualquer modo, esses três exemplares foram selecionados não só pelo aporte imagético, mas pelo que seus manuscritos sugeriam, tendo sido - talvez exatamente por isso - adquiridos pelo sergipano Antônio Marcelino, cuja coleção particular foi doada ao museu Tempostal (onde estão guardados). "A iconografia", situaram Kossoy e Carneiro (1994, p.211), era "o grande desafio" - e isso explicita o motivo de não terem priorizado os breves manuscritos que aqui enfocarei. Para ambos, comumente usada como ilustração - adereço decorativo em apêndice para o esquecimento -, a iconografia devia ser valorizada, pois insinuava ou elidia posturas etnocêntricas, visíveis no relato de viagem e na tese antropológica.

Posteriormente, Schapochnik (1998) publicou ensaio afirmativo do cartão-postal como material inseparável da pesquisa histórica. Na República do início do século XX, tal qual (seu predecessor) o carte-de-visite, a novidade e a mania dos bilhetes ilustrados somavam tipos de negros e indígenas, bem como seus costumes, fazendas de café, homens ilustres, aristocratas, militares, religiosos, cientistas, burgueses e literatos. Na higiênica, segura e aformoseada capital federal cujas "maravilhas de art nouveau" contraditavam 

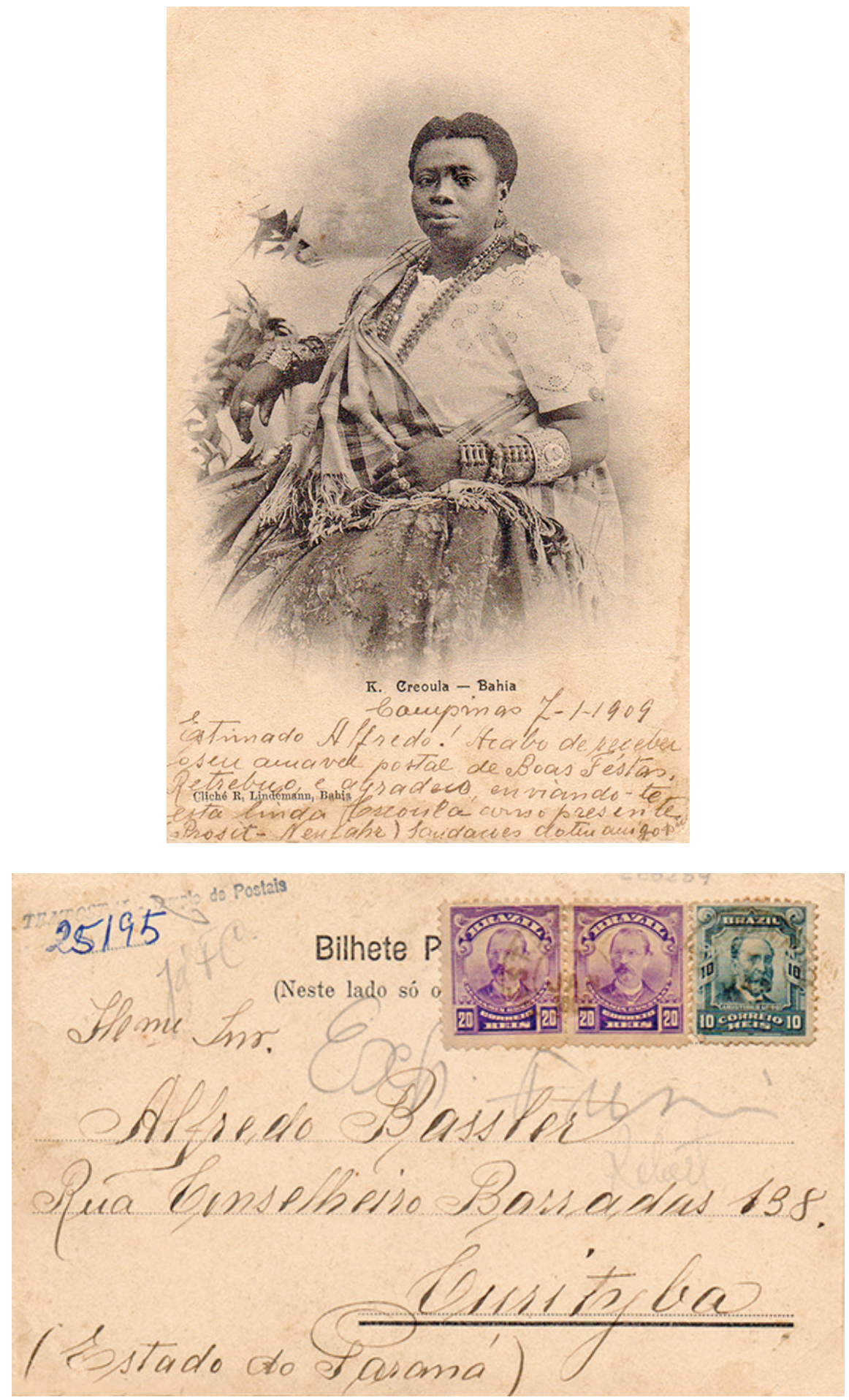

Figura 3: Frente e verso do cartão “K. crioula”, clichê R. Lindemann, 1 jan. 1909 (Museu Tempostal, coleção Antônio Marcelino) 
"quiosques" e "pardieiros" - e também eram erguidas sobre os escombros de teimosos zungus, temíveis cortiços e coloniais solares -, os bilhetes-postais ecoavam a cupidez e o egoísmo do afã europeizante das elites do país (Freyre, 2004, p.716; Benchimol, 1992; Chalhoub, 1996; Soares, 1998). Eram prova de que pipocava uma Paris aqui e ali. E por isso eram espelhinhos que uma civilizada gente trocava entre si, para se ver refletida.

Além de alusões à "negra da Bahia", à "índia Botocudo" e ao "carregador africano", o ensaio de Schapochnik é ilustrado com o mesmo exemplar de "D. crioula". Possivelmente, pela primeira vez, são indicadas as "declarações inusitadas" - íntimas, jocosas -, perfazendo "rica gradação" (Schapochnik, 1998, p.425). Sem aí desdobrar essa instigante percepção, é destacado quanto os postais foram "cânones do art nouveau (o culto da beleza, a valorização da sensualidade, a estilização ornamental)"; tudo isso entremeado à publicidade e ao desejo erótico masculino. "Tão bela" era sua apresentação que eram comprados "em séries, só para encaixilhá-los", fascínio que virou "frenesi" (p.433). Isso aqueceu não só os negócios de fotógrafos, editores, anunciantes, mas os de gráficas, fabricantes (ou importadores) de álbuns, caixas, papel e papelão, selos, carimbos, canetas-tinteiro etc. Nas escrivaninhas, havia os de madames e os de cavalheiros. Havia apetrechos particulares e domésticos; havia coisas especiais para viagens e suas notícias. Por serem versáteis, isto é, ao servirem para uma elementar correspondência ou para viajar sem sair de casa, os postais proliferaram. Ato contínuo, converteram-se em objeto de obsessão de colecionadores, atuantes em clubes inclusive. Schapochnik (1998, p.433) ressalta então que o colecionismo é sentimento de alta pureza pela propriedade privada, sem nem mesmo o objetivo dos lucros. Refúgio do eu, o esmero colecionista é atitude de Narciso. Nada melhor para uma pessoa elegante, culta e civilizada, fora o contato com uma grande e iluminada capital, a sua querida lembrança, o souvenir. Ou guardar ou remeter tipos humanos, populares ou selvagens. Gostos que o cartão satisfazia a contento. Como será visto aqui, será isso - bem isso - o que Dico (remetente, homem colecionador e postalista) deixará gravado por escrito nos bilhetes ilustrados K. e D., postados em 1909 de Campinas, para Alfredo Bassler, em Curitiba.

Páginas adiante, Schapochnik (1998, p.435) retoma aquela percepção instigante, antes em suspenso, e se aproxima ainda mais das partes manuscritas. Para tal, recupera a cena de Freyre na feira da Ladra em Lisboa, relendo notícias de bons ares, mandadas particularmente de Manaus por imigrantes portugueses. Enquanto os vendedores pensavam ser o brasileiro um colecionador, Freyre se entretinha com seus achados científicos a céu aberto. É acrescentado o cuidadoso exame do manuscrito ao raciocínio acerca das coleções, já que sobre a mensagem textual recaiu a lente de aumento de Freyre. Se os bilhetes adquiridos na feira condensavam, em imagens, os semióforos da sociedade capitalista, acolhiam também o influxo da "escrita de si", servindo de encontro entre indivíduo triunfal e a autoelogiosa macronarrativa do século XX (p.437).

Freyre escreveu que o cartão-postal "às vezes ilustrado a cores - brilhante de cores até correspondeu a uma época de euforia e de extroversão na vida nacional", o início do século XX. A pequena cartolina, apesar do tamanho, incrementa o que nela está impresso. Além da natureza, obras de engenharia, fábricas, ferrovias e portos, o palácio do Catete (antiga 
residência de um rico escravocrata do café), ou a vienense Petrópolis, mais os passeios públicos das cidades, hospitais, faculdades, missões religiosas, também as bolsas de valores, exprimiam o desejo de uma "europeização nem sempre feliz". Essa "modernice ostensiva" visava, segundo ele, desmoralizar a suspeita de o Brasil ser "matadouro" da raça civilizada (Freyre, 1978, p.151-156).

Debatendo com Freyre, Slenes foi ao encontro dos textos de Dico a respeito das baianas D. e K. Slenes também teve a fotografia delas em mente o tempo todo. Enviando "linda crioula (não vás ficar apaixonado)", Dico esperava que a correspondência encontrasse seu destinatário bem de "saúde e felicidades". "É assim que um brasileiro - provavelmente um branco da elite paulista -", cogita ele, "se dirige a um amigo". O autor esquadrinha a fonte e repara: "a palavra 'saudades', escrita pelo correspondente no turbante da mulher, contribui para a insinuação erótica". E mais: já que as saudades habitavam a cabeça dela, era a "crioula' [negra nascida no Brasil], não ele" (Dico), quem "mais sente a falta do amigo". "A brincadeira permite-nos flagrar", afirma, "um micromomento na invenção de uma tradição "positiva'" sobre a baiana afrodescendente. Ao lado, o chiste "retrata fato mais sombrio", concernente a "sociedades escravistas: a transformação da mulher de cor no objeto sexual mais cobiçado do homem dominante" (Slenes, 2004, p.15-16). De fato, uma manipulação que coisifica a mulher, conforme assinalou Kossoy, abre oportunidade para uma segunda coisificação, desta vez do remetente. Dico tem o poder de despachar "linda crioula" para o agrado do amigo de Curitiba; e o fez pelo menos duas vezes. Cuidado, alerta, não vá se apaixonar, não a deixe lhe adular demais.

Em nota, Slenes examina o texto que acompanha K., "crioula". "Faz a mesma brincadeira", sintetiza. Dico apela a texto quase idêntico: "enviando-te esta linda crioula como presente", acusa ter recebido votos de boas festas e deseja feliz 1910, no idioma alemão. Sem acesso ao verso do papel, Slenes suspeita "que tenha sido enviado a um brasileiro viajando ou estudando na Alemanha, atividade não rara entre os familiares de fazendeiros do Oeste Paulista". Se o remetente possui sobrenome germânico, seu endereço é na verdade curitibano (e ainda não se sabe se estudou na Alemanha, se para lá viajou, ou se era de família de fazendeiros do Oeste Paulista). O fato é que o postal, sua imagem e o manuscrito continuam a ser inquiridos. E então é feita alusão à reprodução de retratos nos postais celebrativos de linchamentos de homens negros nos EUA, outro "gênero de grande aceitação" no mercado consumidor. Slenes faz fina leitura do texto de um remetente que comemora o "churrasco" de um homem negro assassinado e incendiado, em linchamento, pela multidão branca racista. Fica às claras a sedução da imagem sobre o comprador do cartão e quanto o ato de escrever dá nitidez a essa atração sentida, prova do encontro entre imagem e ação (Slenes, 2004, p.24, 16).

Dos quatro cartões aqui analisados, Christianne Vasconcellos (2006) focaliza primeiro três: dois de Lindemann (as "crioulas" K. e D.) e o de J. Mello (a "crioula da Bahia"). Sem se deter em minúcias, não deixa de notar o desejo masculino perante a "crioula gostosa", enxergando a sua continuidade com preferência similar, manifesta em relatos de viajantes. 

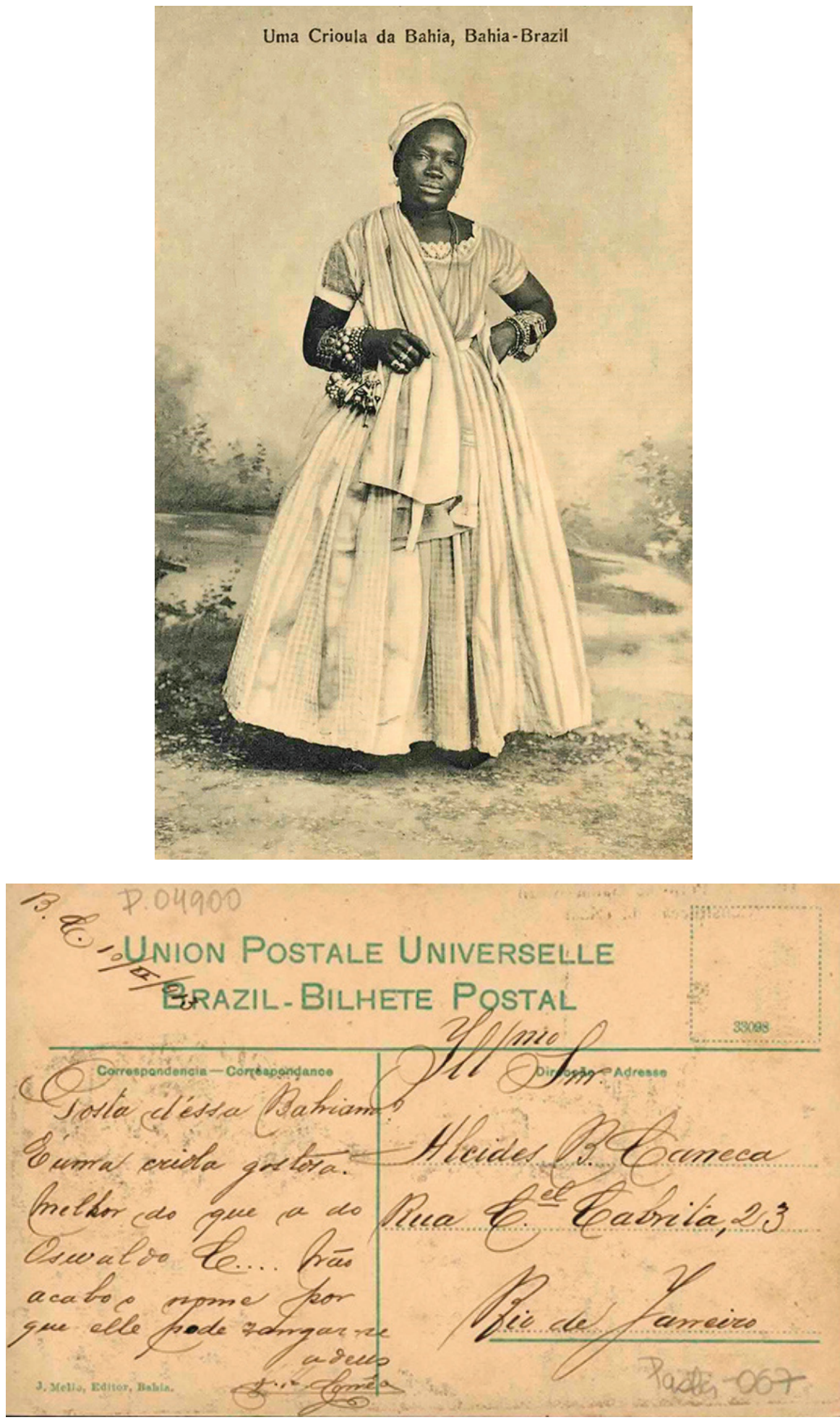

Figura 4: Frente e verso do cartão “Uma crioula da Bahia”, J. Mello - editor, 10 fev. 1913 (Fundação Gregório de Mattos, cx. 67, doc. 4900) 
Mais ainda, ao abordar, num segundo momento, outro cartão (mas com idêntico retrato de "F. carregador africano"), Vasconcellos faz inédita contribuição. Quando imprimiu a mesma foto em outro cartão, Lindemann atestou ser o africano um "ganhador" (designação genérica para proletário que vivia de sua faina diária, desempenhando ofícios diversos, carregador, por exemplo). No enquadramento fotográfico, Lindemann evidenciou no centro da imagem as escarificações na face do modelo, sendo exatamente aí que Vasconcellos se ocupa com o ensaio de Manuel Querino "A raça africana e seus costumes na Bahia", originalmente publicado em 1917. Sem indicar que Querino se serviu de bilhetes-postais, a autora consequentemente não formula a hipótese de ter sido ele o primeiro intelectual brasileiro a ter recorrido ao cartão como fonte, e isso eu faço aqui e agora. Mesmo assim, ela salienta sua importância ao apontar para a argúcia etnográfica de Querino, por ele ter inserido a sua própria legenda - "representante da tribo iorubá" - à preexistente (gravada por Lindemann) "ganhador africano". Outro modelo cujo retrato foi editado em postal avulso (também por Lindemann) é não só um "ganhador africano", mas um trabalhador com etnia específica, no caso, ijexá, de acordo com Querino (1938, p.33). Vasconcellos discerne que ele deixou de lado o termo nagô porque queria discriminar filigranas étnicas. Ela, portanto, especula sobre o relevo das informações dadas (em carne e osso) por velhos carregadores africanos, exatamente por serem proveitosas para perceber nuanças étnicas (Vasconcellos, 2006, p.129, 132, 120). ${ }^{1}$ Quiçá, esses velhos carregadores, perante postais levados até eles por Querino, confirmaram a etnia de cada modelo retratado. Líder destacado do movimento operário, Querino é autor pioneiro, não só por sua apreciação positiva da classe operária, mas por iluminar a máxima importância dos negros tanto no processo de formação da classe trabalhadora brasileira quanto para toda e qualquer riqueza (ou sofisticação) que nossa sociedade desejou ou consumiu (Castellucci, 2015, p.51, 173).

Se Querino redigiu preciosas linhas sobre os cantos de carregadores de Salvador, eles eram, igualmente, do conhecimento de Lindemann, que confeccionou outros bilhetes com ganhadores, itens até hoje de alta procura no mercado desses papéis, valor confirmado em ao menos três outros cartões. O primeiro deles é o do retrato utilizado em "F. carregador africano", que compõe clichê com fotografia da ladeira de São Bento. Em segundo lugar, na letra R. de seu abecedário, Lindemann reuniu em estúdio três "ganhadores africanos" e os eternizou em belíssima composição. Explorando o mesmo magnetismo, J. Mello botou na praça um terceiro cartão, com legenda sugestiva: "Um grupo de velhos carregadores africanos". Diante de tais imagens, remetentes não se continham. Redigiram, por exemplo, "tipo baiano", "porta-fardos", "um de nossos negros" etc. Houve quem dissesse algo sobre as escarificações e quem ainda colou quadra de selos sobre a face do africano, erradicando-o do postal, arrependido - em ato de castração - por ter cedido ao élan do negro. 


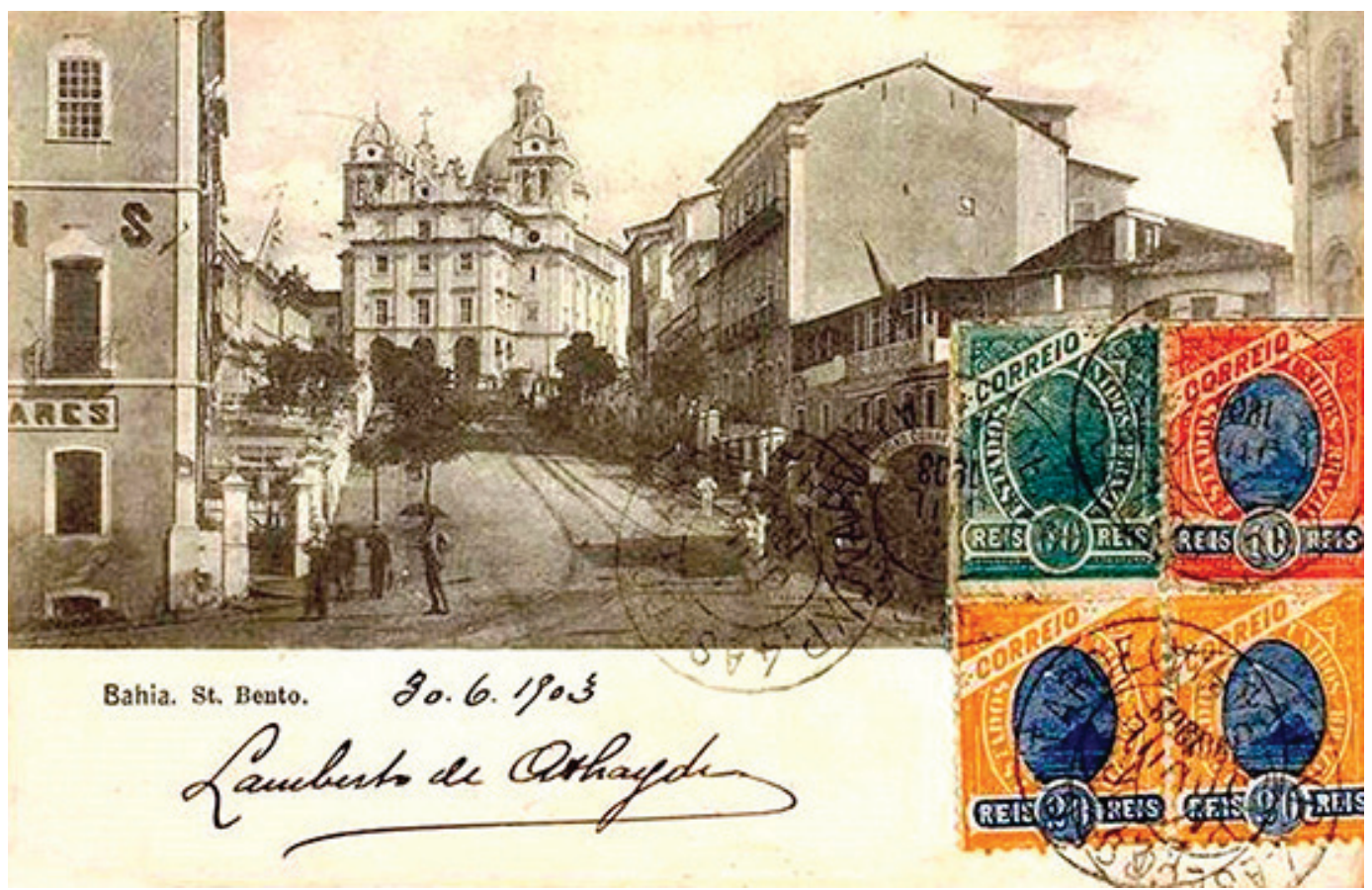

Figura 5: Bilhete, Bahia - São Bento, 30 jun. 1903 (Coleção Negro Postal)

Em 2014, Isis Freitas dos Santos também fez contribuição relevante. Assim como Vasconcellos, ela reproduz os mesmos exemplares K. e D., de Lindemann, e também a "crioula da Bahia", de J. Mello. Sobre este último, Santos constata que a "gostosa" é não só comparada a uma mulher real - "a do Oswaldo C." -, mas avaliada como "melhor". No entanto, o remetente preferiu não se prolongar porque não queria zangar um homem também real, Oswaldo Cruz. Excetuados pequenos deslizes na transcrição do manuscrito alusivo a D., a autora analisa quanto de preconceito o encontro entre imagem e ação cristalizava sobre a mulher negra. Do mesmo modo, Isis Santos reveste com inédita e expressiva nuança a coisificação à qual Boris Kossoy faz referência: a manipulação da imagem do negro pelo retratista, forjado em exótico souvenir, o que proporciona uma segunda abordagem coisificadora no momento que o remetente escreve. Ela beneficia a análise com a necessidade de ponderar a "coautoria" na composição fotográfica. Foi "na dinâmica das ruas que os fotógrafos, assim como os viajantes", avistaram as ganhadeiras. Possuíam ofício, sabiam abordar e cativar clientes, e viviam em sua difícil liberdade: "falam alto, gesticulam, andam com requebros, usam saias de chita, turbantes, chinelas". Seus traços, vestuário e trejeitos são "parte de uma memória construída socialmente". Os "panos da costa, as joias de crioulas" e "determinadas posturas" corporais consistiam em códigos de uma linguagem coletiva específica, não só racial, mas de classe. Na mira da câmera, o retratista esperava exatamente isso: seu comparecimento enquanto tal, sua autorrepresentação em consórcio com a produção de estúdio. Desejava vê-las redivivas 
mesmo entre quatro paredes, com pano de fundo e decoração, destacando o traje e seus adornos, usados no estúdio com o mesmo capricho dos dias de festa. Compareciam, escreve Isis Santos (2014, p.62, 71, 58, 60), "vestidas de si".

Aquilo que Isis percebe em sua saliência era neutralizado como natureza morta, tal qual mesa e vaso florido. Em trecho sobre o álbum de família, Pinho (1942) cita crônica de 1863. Nesta, garante-se: "não há quem não tenha um álbum pelo menos, porque a maior parte tem-nos às dúzias". Iniciados pelos pater familias, vinham "pela ordem rigorosa das idades o irmão conselheiro, o irmão aspirante de Marinha, a irmã que já solfeja a valsa da moda"; sucessão encerrada pela "irmã que mama ainda, e cujo rosto se esconde junto da face escura da ama, retratada por concomitância" (p.347). Como se lê, a ama em quem se oculta o rosto da sinhazinha é "retratada por concomitância". Sua presença é apoio, tecido humano de refúgio.

O fato de a ama sair fotografada como uma coisa ajuda a entender sua ausência nas fontes iconográficas do arquivo pessoal do historiador Wanderley Pinho, confiado pelo próprio ao Instituto Histórico e Geográfico Brasileiro. A família aparece congregada em torno do pater familias, que foi governador da Bahia, além de senhor de engenho. Membros masculinos e femininos estão dispostos isoladamente em diversos retratos, em qualquer idade. Mesmo quando crianças, nem por concomitância transparece a mulher em cujo colo dengoso muxoxaram. Uma das razões para isso talvez esteja no abafamento da "origem africana" do sogro, o barão de Cotegipe, João Maurício Wanderley, apagamento que Grinberg (2002, p.441) ressaltou. Adversários políticos, a autora detectou, achacavam Cotegipe por pertencer à "raça mestiça de branco e preto" e ser desfavorável à abolição. Traços não brancos foram ansiosamente perdidos na união conjugal da filha dos Wanderley aos Araújo Pinho. Disso decorre que nem por concomitância parece haver espaço para a ama. ${ }^{2}$

É, portanto, necessário discernir os distintos usos da fotografia impressa em suporte cartolinado. Conforme Koutsoukos (2009, p.313), a ama podia ter peso positivo no sentimento de uma história íntima. Mas esta, como se vê aqui, podia ser posta no esquecimento na hora de imortalizar uma família, em seu acervo particular sob a curadoria de uma instituição de memória. Além disso, expediam-se cartões para o deleite narcisístico. Assim, a bico de pena, duas ou três linhas que se supunha saber sobre ela (ou ele) reenquadravam o retrato do qual a agência subalterna era coautora, pendurando-a novamente como coisa. Mensagens desse teor não são, porém, comuns entre familiares de elite que se correspondiam constantemente, valendo-se do caráter prático, versátil e expresso dos bilhetes-postais, o que se vê com clareza nas extensas coleções geradas por famílias da elite. Coleções que ao longo dos anos se formaram entre parentes em circuito fechado circulam felicitações, lembranças, estimas, alusões a detalhes cotidianos, à saúde ou a festejos. Não trazem translúcidas referências de hierarquia social sobre tipos, lugares e situações. Isso em geral sucede entre viajantes ou correspondentes a distância.

Apesar de não fazer referência aos postais aqui em mira, Freyre tem de novo algo a dizer. Seu livro O escravo nos anúncios de jornais tratou da relação entre tipos sociais e indivíduos, suas roupas e marcas corporais. Os anúncios, explica, tencionam engatilhar respostas sensoriais de familiaridade, associação e automatismo; e assim buscam capturar, deter 
e absorver a atenção de quem os percebe. No caso de seres humanos à venda, as ofertas interessam à pesquisa pelo que sugerem das "atividades dos anunciantes" - cuja cultura e etnia eram dominantes - perante os "valores físicos, econômicos, culturais" de homens e mulheres da "cultura e etnia dominadas". "Dramas de três linhas, romances em duas linhas e meia", nos minúsculos caixotes dos anúncios eram encontrados vestígios das avaliações que autoproclamados senhores faziam sobre as "qualidades de corpo e de comportamento" dos escravizados (Freyre, 1979, p.XLVIII, 3).

À vista dos resultados obtidos - depois de encarado o desafio de analisar os códigos da técnica fotográfica e da expressão plástica, uma vez examinados os estúdios, os modelos e seus retratistas (Mauad, 2013) -, hoje é possível acrescentar as subaproveitadas declarações redigidas em somatório à figura veiculada nos cartões. Nas diferentes formas em que circularam, os cartões constituíram repositório de mensagens variadas, trazendo consigo diversas marcas (fotógrafo e editor, modelos, correspondentes, a própria historiografia), superfície de camadas variadas. A atitude de manifestar-se por escrito sobre um lugar, seus tipos e costumes, servindo-se do exíguo espaço disponível, ou mesmo abrindo lugar onde não havia, aponta inédito caminho de pesquisa. Pequenos pedaços de papelão de art nouveau, os postais engajaram-se na tragédia dessa mania de uma Europa superior, consistindo em matéria para simbiose entre imagem e texto. Suportes de encontro entre o retratar (e se dar ao retrato) com a interação de quem deixa algo gravado à mão dão a ver, de modo indiciário, o que uma classe social, composta por uma etnia e uma cultura dominantes, pensava da cultura e das etnias das classes subalternas, em particular sobre seus tipos e costumes, em cenas corriqueiras, sitas em logradouros públicos ou privados (havendo ainda a possibilidade de recriação cenográfica de tais lugares em estúdio). Tal qual uma solução deitada a conta-gotas, os cartões foram aplicados com olhar pressuroso sobre a narrativa embranquecedora do progresso capitalista, superelogiosa da imigração europeia.

Não era, porém, uma correspondência que ocasionava extravagâncias confessionais demoradas e de alta frequência. Antes de mais nada, eram impressos e adquiridos para recados, encomendas, pedidos ou avisos, protestos de estima, votos de boas festas, lembranças ou parabéns, expressões de afeto. Ou propaganda e comércio. A fim de elaborar uma análise inédita que se valha de seu potencial até agora pouco explorado, é preciso ir além dos quatro exemplares que atraíram e capturaram o olhar dos pesquisadores mas não estimularam o amplo manuseio de milhares de outros cartões (e dezenas ou centenas de exemplares idênticos), os quais ainda não receberam a mesma atenção. É possível surpreender as indiscrições que, volta e meia, são expedidas com a imagem, seja a que faz confissões íntimas, que comenta um lugar ou tipo humano, seja a que se pretende científica, remetida a par, colecionador, alguém civilizado (semelhantemente etnocêntrico) (Alloula, 1986; Pollen, 2009; Onken, 2014; Harris, 2015).

A pesquisa, quer de centenas de exemplares da mesma peça, quer de milhares de itens diversos, alcançará o discrepante texto que, premeditado ou impulsivo, complementa - ou suplementa - as cuidadosas intenções de fotógrafos e editores. Três ou quatro linhas indagam a respeito do medo que se pode sentir diante de um homem negro; ou também rejeitam um lugar por sua letal insalubridade tropical. Algumas vezes, classificam ou hierarquizam tipos humanos ou grupos sociais. Outras vezes, expõem o desejo do homem branco sobre 
a mulher subalterna "exótica", não apenas a negra. Tais linhas são um contraste com a pacificação - a paisagem aplainada de suas inquietudes - que tanto Schwarcz (2014) como Muaze (2017) afirmam predominar nas fotografias de Ferrez, várias delas reproduzidas em cartões-postais. Quando as mensagens textuais tratam da relação entre senhores e subalternos, evidenciam a posição de diferença de quem enxerga a desigualdade a partir de cima. Ao contrário do argumento de Freyre acerca dos anúncios de escravos, que, segundo ele, atestam a avançada dianteira do português abrasileirado do século XIX (reelaborado no falar do povo), evidenciando feliz adaptação europeia aos trópicos, os cartões-postais, acrescidos de selos e carimbos, estudada caligrafia, idiomas estrangeiros (o francês amplamente), dão materialidade ao que homens e mulheres de uma elite "superior" pensavam dos outros com quem mantinham relações de trabalho, classe, gênero, raça. Nem tudo, no mesmo apertado suporte de imagem e palavras, é harmonia ou confraternização, encontro ou miscigenação.

Se os de baixo conseguiam viver de si e estavam por isso mesmo vestidos de si - se haviam conseguido reter a humanidade roubada pelo cativeiro -, os de cima gostavam de exibir suas credenciais. Qualquer encontro que possa ter ocorrido entre as classes se deu por sobre essa nítida divisória de classe social. O consumo vistoso e raffiné, as cultivadas letras e as mensagens dos postais, faziam os de baixo ver que os de cima eram ciosos de suas posições. Como ensina Thompson (1987, p.61-62), os mundos do trabalho em geral retrucam com a preservação de "seus traços mais robustos e desordeiros", alimentando "certos valores - espontaneidade, capacidade para a diversão e lealdade mútua -, apesar das pressões inibidoras" impostas pela desigualdade social. No que diz respeito à manifestação erótica, os cartões são uma fonte que dispara o alerta ante a quase impenetrável privacidade dos de cima. Uma cidade - a próspera Pelotas, por exemplo - tem ares de Paris (luzes, boas comida e bebida, progresso e riqueza, homens cavalheiros e de ciência). A manifestação do desejo erótico, ou do preconceito de superioridade, remete a essa história íntima, recorrente em recinto privado (sem freios), onde um homem (ou o civilizado) crê fazer o que quer, perante uma mulher subalterna e vulnerável (ou selvagem). No que alude aos tipos e costumes, em seus lugares de atuação (que o estúdio fotográfico buscava remontar), os cartões comprovam a resistência e a resiliência de sujeitos que deviam estar em extinção (os índios) ou em acentuada curva de declínio demográfico (os negros). O inusitado de certas mensagens acopladas às imagens por indivíduos civilizados - com seus ares de superioridade ou receios - denota que os de cima não eram tão seguros de si nem mesmo diante de retratos, o que os levava a gravar, por escrito, sua pretensa superioridade na relação, mesmo em um pedacinho de papelão voador.

\section{NOTAS}

${ }^{1}$ Segundo Reis (1993, p.10), os nagôs "vieram de uma terra iorubá dividida em subgrupos muitas vezes hostis entre si, e ainda separados por afiliação religiosa e lealdades políticas. Os iorubás dos reinos de Oyo, Egba, ljebu, llexa, Ketu tornaram-se nagôs baianos através de complexas trocas e convergências".

${ }^{2}$ Note-se o recolhimento de outro tipo de bilhete, também para fins da custódia institucional. Confiados em mãos por portadores, há bilhetes com rogos de proteção, colocação, nomeação, promoção etc. Pequenos e numerosos, foram mantidos como valiosos documentos, mesmo os que tratam de sujeitos humildes. Guardados talvez para gravar o débito gerado pelos favores concedidos, são encaminhados a arquivo ou museu como prova da importância de quem os atendia (Carvalho, 2007, p.9). 


\section{REFERÊNCIAS}

ALLOULA, Malek.

The colonial harem. Minneapolis: University of Minnesota Press. 1986.

BENCHIMOL, Jaime.

Pereira Passos: um Haussmann tropical: a renovação urbana da cidade do Rio de Janeiro no início do século XX. Rio de Janeiro: Secretaria Municipal de Cultura. 1992.

CARVALHO, José M. de.

Introdução. In: Fundação Biblioteca Nacional. Arquivo Tobias Monteiro: inventário analítico. Rio de Janeiro: Fundação Biblioteca Nacional. p.916. 2007.

CASTELLUCCI, Aldrin.

Trabalhadores e política no Brasil: do aprendizado do Império aos sucessos da Primeira República. Salvador: Editora da Uneb. 2015.

CHALHOUB, Sidney.

Cidade febril. São Paulo: Companhia das Letras. 1996.

FREYRE, Gilberto.

Ordem e progresso. São Paulo: Global Editora. 2004.

FREYRE, Gilberto.

O escravo nos anúncios de jornais brasileiros do século XIX. São Paulo: Editora Nacional. 1979.

FREYRE, Gilberto.

Informação, comunicação e cartão postal. In: Freyre, Gilberto. Alhos e bugalhos: ensaios sobre temas contraditórios, de Joyce à cachaça; de José Lins do Rego ao cartão postal. Rio de Janeiro: Nova Fronteira. p.146-161. 1978.

GRINBERG, Keila.

José Maurício Wanderley. In: Vainfas, Ronaldo (Org.). Dicionário do Brasil imperial. Rio de Janeiro: Objetiva. p.441-442. 2002.

HACKLER, Ewald.

O postal ilustrado (1898-1930). In: Vianna, Marisa (Org.). "...Vou pra Bahia": cidade do Salvador em cartões-postais (1898-1930). Salvador: Bigraf. p.13-20. 2004.

HARRIS, Jessica B.

Postcards of food from Africa and diaspora. $V Q R$, v.91, n.2. Disponível em: <https://www. vqronline.org/essays-articles/2015/04/squaremeal>. Acesso em: 10 ago. 2020. 2015.

KOSSOY, Boris.

Origens e expansão da fotografia no Brasil. Rio de Janeiro: Funarte. 1980.

KOSSOY, Boris; CARNEIRO, Maria. O olhar europeu: o negro na iconografia brasileira do século XIX. São Paulo: Edusp. 1994.
KOUTOSOUKOS, Sandra.

Amas mercenárias: o discurso dos doutores em medicina e os retratos de amas. História, Ciências, Saúde - Manguinhos, v.16, n.2, p.305324. 2009.

MAUAD, Ana.

Fotografias com corpo e alma... Afro-Ásia, n.48, p.439-446. 2013.

MUAZE, Mariana.

Violência apaziguada: escravidão e cultivo do café nas fotografias de Marc Ferrez (1882-1885). Revista Brasileira de História, v.37, n.74, p.33-62. 2017.

ONKEN, Hinnerk.

Visiones y visualizaciones: la nación en tarjetas postales sudamericanas a fines del siglo XIX y comienzos del siglo XX. Iberoamericana, v.14, n.56, p.47-69. 2014.

PINHO, Wanderley.

Salões e damas do Segundo Reinado. São Paulo: Livraria Martins. 1942.

POLLEN, Annebella.

Sweet nothings: suggestive Brighton postcard inscriptions. Photography and Culture, v.2, n.1, p.77-88. 2009.

QUERINO, Manuel.

Costumes africanos no Brasil. Rio de Janeiro: Civilização Brasileira. 1938.

RAMOS, Clarice.

Postais para ver: cartofilia no Brasil na primeira metade do século XX na coleção de Estella Bustamante. Dissertação (Mestrado) - Instituto de História, Universidade Federal Fluminense, Niterói. 2018.

REIS, João.

A Greve Negra de 1857 na Bahia. Revista USP, n.18, p.6-29. 1993.

SANTOS, Isis.

"Gosta dessa baiana?" A construção da "baiana" como símbolo local e as dinâmicas sociais que a envolvem na Bahia (1880-1920). Dissertação (Mestrado) - Faculdade de Filosofia e Ciências Humanas, Universidade Federal da Bahia, Salvador. 2014.

SCHAPOCHNIK, Nelson.

Cartões postais, álbuns de família e ícones da intimidade. In: Sevcenko, Nicolau (Org.). História da vida privada no Brasil. v.3. São Paulo: Companhia das Letras. p.423-512. 1998.

SCHWARCZ, Lilia.

Lendo e agenciando imagens: o rei, a natureza e seus belos naturais. Sociologia e Antropologia, v.4, n.2, p.391-431. 2014. 
SLENES, Robert.

Prefácio. In: Gomes, Tiago. Um espelho no palco: identidades sociais e massificação da cultura no teatro de revista dos anos 1920. Campinas: Editora da Unicamp. p.15-26. 2004.

SOARES, Carlos E.L.

Zungu: rumor de muitas vozes. Rio de Janeiro: Aperj. 1998.
THOMPSON, Edward Palmer.

A formação da classe operária inglesa. v.1. Rio de Janeiro: Paz e Terra. 1987.

VASCONCELLOS, Christianne.

O circuito social das fotografias da gente negra:

Salvador, 1860-1916. Dissertação (Mestrado)

- Faculdade de Filosofia e Ciências Humanas,

Universidade Federal da Bahia, Salvador. 2006.

\section{$\rightarrow \rightarrow \rightarrow<<<$}

